\title{
Tek Taraflı İnmemiş Testisi olan Infantlarda Orşiopeksi Sonrası Serum AMH Seviyelerinin Değerlendirilmesi
}

\author{
Evaluation Serum AMH Levels After Orchiopexy in Infants with Unilateral Undescended Testis
}

${ }^{1}$ Murat Topçuoğlu, ${ }^{2}$ Veysel Nijat Baş

${ }^{1}$ Alanya Alaaddin Keykubat Universitesi Üroloji Ana Bilim Dalı,Antalya,, Türkiye

${ }^{2}$ Kütahya Sağlık Bilimleri Üniversitesi, Çocuk Sağlığı ve Hastalıkları Ana Bilim Dalı, KütahyaTürkiye

\section{Özet}

Serum antimüllerian hormon (AMH) değeri postnatal dönemde 1 yaşa kadar stabil seyreder. Çalışmamızda tek taraflı kriptorşidizm nedeniyle orşiopeksi uygulanan yaşları 3-12 ay olan çocuklarda preoperatif dönemde serum AMH değerleri belirlendi ve postoperatif dönem serum AMH seviyesinde ki değişim incelendi. Çalışma popülasyonu, tek taraflı testisleri palpe edilen ve orşiopeksi uygulanan bir yaș altı 77 kriptorşid çocuktan oluşuyordu. İnmemiş testis tanısı takiben tüm hastalara inguinal orşiopeksi yapıldı. Orşiopeksi öncesi serum AMH seviyeleri ve testis boyutları belirlendi ve orşiopeksi sonrası altıncı ayda AMH seviyeleri ve testis boyutları karşılaştırıldı. Ameliyat sonrası altıncı ay kontrol döneminde ölçülen serum AMH değerleri ameliyat öncesi ölçülen serum AMH değerlerine göre anlamlı yüksek bulundu. Ameliyat sonrası yapılan fizik muayenede bütün testisler skrotumda izlendi. Ameliyat öncesi ve sonrası dönemde orşiopeksi yapılan testis boyutlarında farklılık izlenmedi. AMH, iyi bilinen bir sertoli hücre belirteci olarak gonadal fonksiyonu yansıtabilir. İnfantil mini-puberte olarak adlandırılan dönemi takiben diğer gonadal hormonların aksine serum AMH serumda stabil seyreder. AMH, özellikle bu dönemde testis fonksiyonlarını göstermede diğer serum belirteclerine göre daha avantajlıdır. Calısmamızda orssiopeksi sonrası serum AMH seviyesinde anlamlı artış izlendi. Özellikle doğum sonrası ilk yılda testis fonksiyonlarının bir göstergesi olarak orşiopeksi öncesi ve sonrası AMH düzeylerinin karşılaştırılması tedavinin etkinliğini belirlemede de faydalı olabilir.

Anahtar Kelimeler: Antimüllerian hormon, Orșiopeksi, İnfertilite

\section{Abstract}

In boys, serum anti-Müllerian hormone (AMH) reflects Sertoli cell function, seminiferous tubular integrity and testicular function. Serum $\mathrm{AMH}$ value remains stable until one year of age in the postnatal period. In our study, preoperative and postoperative serum $\mathrm{AMH}$ values were compared in infants between age of 3-12 months who underwent orchiopexy due to unilateral cryptorchidism. The study population consisted of 77 cryptorchid children under one year of age who had unilateral palpabl testis and underwent orchiopexy. Following the diagnosis of undescended testis, all patients underwent inguinal orchiopexy. Serum AMH levels and testicular size were evaluated before the orchiopexy, and AMH levels and testicular size were compared at the sixth month following orchiopexy. Serum AMH values measured in the postoperative sixth month control period were significantly higher than preoperative serum AMH values. All testicles were examined in the scrotum in the postoperative period. There was no difference in size of testes that underwent orchiopexy before and after surgery. AMH may reflect gonadal function as it is a well-known Sertoli cell marker. Unlike the other gonadal hormones, AMH remains stable in the serum following the period called infantile mini-puberty. Particulary in this period AMH is more advantageous than other serum markers in demonstrating testicular functions. In our study, a significant increase in serum AMH level was observed after orchiopexy. As an indicator of testicular function, especially in the first year of postnatal period, comparing AMH levels before and after orchiopexy may also be useful in determining the effectiveness of treatment.

Keywords: Antimullerian hormone, Orchiopexy, İnfertility. 


\section{Giriş}

İnmemiş testis, (İT) miadında doğan tüm erkeklerin \%3-5'ini, preterm veya düşük doğum ağırlıklı erkek bebeklerin yaklaşık $\% 23$ ' ünü etkileyen erkek genital sisteminin en yaygın görülen bozukluğudur (1-2). Doğum sonrası izlenen spontan inişle beraber İT oranı $\% 1$ 'e kadar geriler (3). İT etiyolojisi literatürde halen tartışmalı bir konudur. Hormonal düzenlemedeki bozukluklar ve farklı gen kusurlarının bu süreçte önemli rolünün olduğuna inanılmaktadır (4). Testisin skrotuma inişi iki aşamada gerçekleşir. Gestasyonun 10-15. haftasında gerçekleşen ve abdominal evre olarak adlandırılan ilk evre androjenden bağımsızdır (5). Bazı çalışmalarda Anti-Müllerian hormonun $(\mathrm{AMH})$ testisin inişinin birinci evresi olan abdominal fazda büyük oranda rol oynadığ 1 kabul edilmekle birlikte bu inişte AMH 'nın bir etkisinin olmadığını öne süren kanıtlarda vardır (5-7). İnişin ikinci safhada ise testisler, androjenlerin ve karın içi basıncının etkisiyle iç inguinal halkadan skrotuma göç eder (8). $\mathrm{Bu}$ safhalarda herhangi bir problem sonucu gelişen İT etyolojisinde primer testis gelişim bozukluğununda da etkisi olabilir ve İT altta yatan testiküler gelişim patolojisinin bir işareti olabilir. Bu noktada İT durumunda testislerin fonksiyonel durumunun değerlendirilmesi tedaviden görülecek yararı ön görmede faydalı olabilir. $\mathrm{Bu}$ değerlendirmede kullanilabilecek serum gonadotropinler, testosteron, INSL3, AMH ve inhibin B gibi hormonların seviyeleri postnatal 2-3. ayda pik yapar. $\mathrm{Bu}$ artış sonrası $\mathrm{FSH}, \mathrm{LH}$, testosteron ve INSL3 seviyeleri, genellikle 4.ayda tipik prepubertal çocukluk seviyelerine hizla düşerken sertoli hücreleri aktif kalır ve dolayısıyla serum AMH seviyeleri diğer hormonlara göre göreceli olarak yüksek kalmaya devam eder (9-10). Bundan dolay1 prepubertal dönemde testiküler fonksiyonları değerlendirme için Sertoli hücrelerinin salgıladığı AMH seviyeleri daha güvenilirdir. İT tedavisinin sonuçlarını değerlendirmede tedavi öncesi ve sonrası dönemde testislerin fonksiyonel kapasitesinin ölçülmesi önemli bir rehber olma potansiyeli taşır. Bu klinik çalışmada öncelikle tek taraflı palpe edilebilen inmemiş testisli erkek çocukların orşiopeksi işlemi öncesi ve sonrası serum AMH düzeylerini karşılaştırıldı. Yaş ile ameliyat öncesi serum AMH değeri, ameliyat sonrası serum AMH değeri ve serum AMH değişimi arasında korelasyon olup olmadığını incelendi.

\section{Gereç ve Yöntem}

$\mathrm{Bu}$ prospektif çalışma, 2013-2014 tarihleri arasında çocuk endokrinoloji polikliniğine tek taraflı inmemiş testis şikayeti ile başvuran ve yaşları 3 -12 ay arası değişen 77 erkek çocuk ile yapıldı. Çalışmanın etik kurulu, 1964 Helsinki Bildirgesi'nde ve sonraki değişikliklerinde belirtilen etik standartlara uygun olacak şekilde Erciyes Üniversitesi Etik Kurulu (Karar no:2013/122) tarafindan alındı. Tüm ebeveynlere çalışma hakkında detaylı bilgi verildi ve yazılı onamları alındı. Gonadal muayene aynı pediatrik endokrinolog tarafindan yapıldı. İnmemiş testis tanısı skrotumda tek taraflı testisin yokluğu ve aynı taraf testisin fizik muayene ve/veya yüzeyel ultrasonografi ile inguinal kanalda saptanmas ile kondu. Prader'in orkidometresi ile karşılaştırılarak testis hacimleri ölçüldü. Testislerin yerleşimi, pubik kıllanma durumu ve Marshall-Tanner'a göre genital gelişim incelendi. İşlemden önce, tüm çocuklar kromozomal anormallikleri dişlamak için karyotiplemeye tabi tutuldu. Kromozom anomalileri saptanan, fitık, mikropenis, cinsel gelişim bozukluğu, genital veya abdominalpelvik cerrahi geçiren, gonadal aksı etkileyen hastalığ 1 olan, ilk değerlendirmeden önce radyoterapi veya kemoterapi uygulanan ve testis fonksiyonunu etkilediği bilinen genetik sendromları olan hastalar çalışma dışı bırakıldı. İnmemiş testis tanısı takiben tüm hastalara inguinal orșiopeksi yapıldı. Hastalar daha öncesinde hormonal tedavi dahil herhangi bir tedavi almadılar. Çalışmanın ana sonuç kriteri AMH'nun serum konsantrasyonuydu. Çocukların serum AMH seviyeleri, orşiopeksi işleminden 1 gün önce ve 6 ay sonra ölçüldü. EDTA içeren tüplere antekübital venden kan örnekleri alındı. Serum örnekleri santrifüjleme ile hücrelerden ayrıld. Serum AMH seviyeleri immünoenzimatik sandviç yöntemiyle ölçüldü. 


\section{Ístatistiksel analiz}

Tanımlayıcı istatistikler için ortalama, standart sapma, medyan, minimum, maksimum değer frekans ve yüzde kullanıldı. Değişkenlerin dağılımı kolmogorov-simirnov testi ile kontrol edildi. Tekrarlanan ölçüm analizleri için Wilcoxon testi kullanıldı. Korelasyon analizinde Spearman kullanıldı. Hayatta kalma analizinde Kaplan-Meier kullanıldı. Etki düzeyini göstermek için ROC analizi kullanıldı. İstatistiksel analizler için SPSS 27.0 kullanild1.

\section{Bulgular}

Ameliyat öncesi tüm kriptorşidik testisler normal boyuttalardı ve ameliyat sirasında intraoperatif inguinal bölgede palpe edildi bulundu ve orşiopeksi ile tamamı başarılı bir şekilde skrotuma indirildi. Ameliyat sonras 1 altınc1 ay yapılan fizik muayenede bütün testisler skrotumda izlendi. Ameliyat öncesi ve sonrası dönemde serum AMH ölçümünün sonuçları Tablo 1'de gösterilmektedir. Ameliyat sonrası altıncı ay kontrol döneminde ölçülen serum AMH değerleri ameliyat öncesi ölçülen serum AMH değerlerine göre istatistiksel anlamlı yüksek bulundu. (Şekil 1) Ameliyat öncesi ve sonrası dönemde Prader orkidometri ölçümlerinde farklılık izlenmedi

Tablo 1. Grupların serum AMH preoperatif ve postoperatif değerleri.

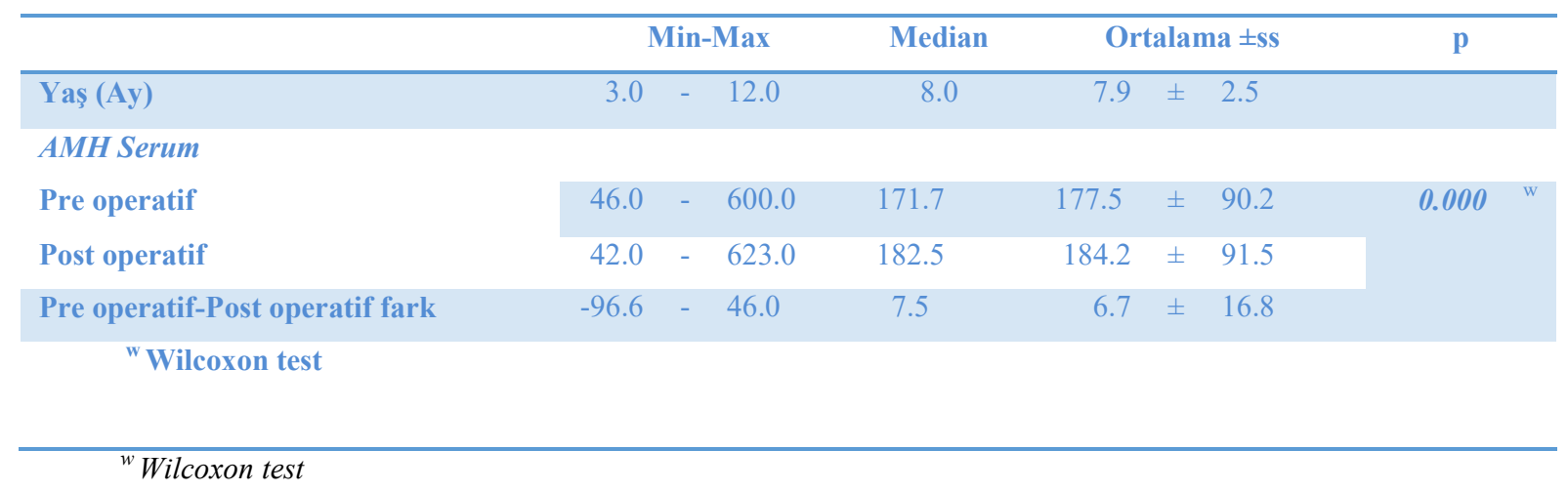

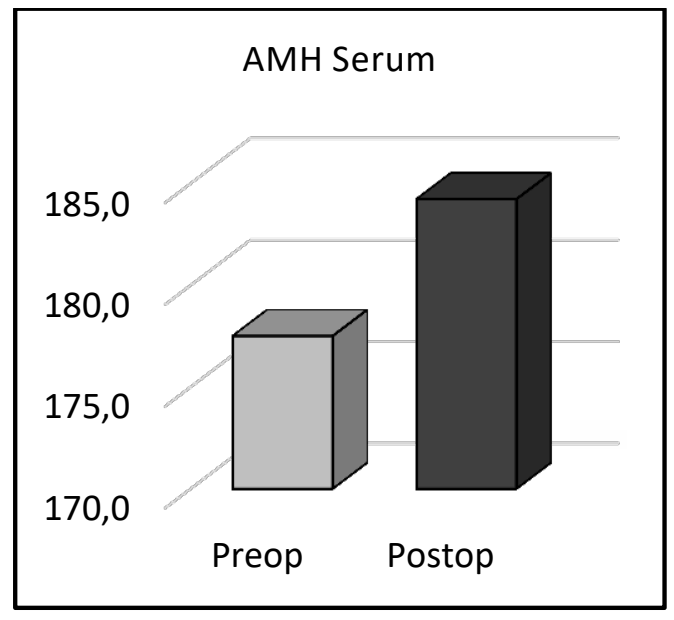

Şekil 1. Preoperatif ve postoperatif ortalama serum AMH değişimi 
Tablo 2. Yaş ile preoperatif AMH değeri, postoperatif AMH değeri, postoperatif AMH değişimi arasında değişim.

Serum AMH seviyeleri

\begin{tabular}{lcccc}
\hline & & Preoperatif & Postoperatif & Postoperatif-Preoperatif \\
& & & Fark \\
\hline Yaş (Ay) & $\mathrm{r}$ & -0.107 & -0.089 & 0.152 \\
& $\mathrm{p}$ & 0.357 & 0.446 & 0.189 \\
Spearman Korelasyon & & & \\
\hline
\end{tabular}

\section{Tartışma}

Fizyolojik olarak iki aşamalı bir süreçten oluşan testis inişi sürecinde birçok genetik ve endokrin faktör rol oynar ve bu sürecin sağlıklı olması büyük oranda hipotalamushipofiz-testis hormonal ekseninin düzgün işleyişine bağlidir. Testiküler iniş patofizyolojisinde etkisi olduğu düşünülen ve Müllerian inhibe edici madde (MIS) olarak da adlandırılan AMH, dönüştürücü büyüme faktörü ailesine ait dimerik bir glikoproteindir (11). AMH'nun testis inişi üzerindeki rolünü inceleyen ve farklı görüş bildiren çalışmalar vardır, ancak bunlar tek taraflı İT hastalarını incelediğimiz çalışmamızdan farklı olarak genel olarak deneysel veya bilateral palpe edilemeyen testisleri içeren klinik çalışmalardır (12-15). Erkeklerde AMH, Sertoli hücre olgunlaşmasını yansıtır ve fetal yaşamdan ergenliğe kadar testiste sertoli hücresi tarafından üretilir (16). AMH, yaşam boyunca tespit edilebilen ve özellikle prepubertal dönem göreceli olarak yüksek ve stabil seviyede kalan bir testis hormonudur ve sertoli hücre belirteci olmasından dolayı gonadal fonksiyon hakkında bilgi verebilir (17). İnfantil mini-puberte olarak adlandirilan dönemi takiben FSH, LH, testosteron ve INSL3 seviyeleri, genellikle 4-6 aylikken prepubertal çocukluk seviyelerine hızla geriler (18). Kriptorşidizmli hastalarda hipofiz-testis eksenini değerlendirmek amacıyla, Leydig hücre belirteçleri olan testosteron ve INSL3 serum seviyeleri de farklı çalışmalarda değerlendirilmiştir ama bazal testosteron gibi INSL3 seviyeleri de diğer çalışmalarda vurgulandığı gibi doğumdan itibaren azalarak postnatal 3 ve 6 . ay dönemde çok düşük hatta tespit edilemez seviyeye geldiğinden fonksiyonu göstermede çok bilgilendirici değildir (19). Sertoli hücrelerinin aktivasyonuna bağlı olarak bahsedilen hormonların aksine serum AMH seviyesinin doğumu takiben birinci y1la kadar serumda stabil seyreder. 1 yaş öncesi gonadal fonksiyonun değerlendirilmesinde oldukça değerli olan AMH'nun diğer bir avantajı da stimülasyon testine gerek kalmaksızın gonadal fonksiyonun hakkında bilgi verebilmesidir (9,20-21). Çalışmamızda, AMH'nun bahsedilen bu serum patterni dikkate alarak hasta populasyonumuzu 1 yaş öncesi ITT vakalarından oluşturduk. IT tanısı konulduğunda ve tedavi sonrası testis fonksiyonunun değerlendirilmesi ve karşılaştırılması uzun süreli takiplerde tedavinin etkinliğinin değerlendirilmesine yardımcı olabilir. $\mathrm{Bu}$ bilgilerin 1şı̆̆ında literatürde orşiopeksi öncesi ve sonrası AMH düzeylerinin karşılaştırılmasının özellikle tedavinin etkinliğini belirlemede yararlı olabileceği öne sürülmekle birlikte orşiopeksinin serum AMH düzeyleri üzerindeki etkisi şimdiye kadar çok kısıtlı sayıda çalışmada incelenmiştir. Biz bu bilgiler 1şı̆̆ında öncelikle operasyon öncesi dönemdeki bazal serum AMH değerlerini genel literatür ile karşılaştırdık. Hastalarımızda preoperatif serum AMH değerlerinin ortalaması geniş vaka sayılı çalışmalarda rapor edilen kontrol hastalarının referans aralığ 1 olarak kabul edilen 5-95 persentil aralık değerleriyle korele idi (22). Bizim bulgumuza benzer şekilde, tek taraflı IT hastalarını değerlendirildiği bir çalışmada, vaka ve kontrol grubu arasinda bazal serum AMH düzeyleri açısından istatistiksel olarak anlamlı bir fark rapor etmemişlerdir (23). Literatürde kriptorşidik hastaların çoğunda referans aralığında serum AMH seviyeleri bildirilse de, bazal değerlendirmede azalmış 
serum AMH saptanan çalışmalarda yayınlanmıştır ve bu bulgu çocukluk döneminde etkilenmiş bir testis fonksiyonuna işaret edebilir. (22-24). Bununla birlikte karşılaştırılan çalışmalarda serum AMH ölçümü için farklı laboratuvarlarda, farklı teknikler ve reaktiflerin kullanılması da serum değerlerin değerlendirilmesini zorlaştırmaktadır (25-26).

Bu karşılaştırmayı zorlaştıran diğer bir faktör ise IT vakalarında testislerin farklı derecelerde migrasyon defektine sahip olmaları ve farklı lokalizasyonlarda olmasıdır. Çalışmamızda tedavi öncesi dönemde hastalarda normal referans aralığında serum $\mathrm{AMH}$ değerleri saptamamıza rağmen hasta popülasyonumuz karşılaştırılan çalışmalara göre genel olarak daha hafif migrasyon defektine sahip olan çocuklardan oluşuyordu.

İnmemiş testisin cerrahi tedavisinde geleneksel başarı kriteri testisin skrotuma atrofiye gitmeden indirilmesidir (27). Çalışmamızda kontrol döneminde bütün hastalarda ultrasonografi sonuçlarına göre testis skrotumda ve normal boyutta izlendi. Ama bu kriter yüksek infertilite oranlarını göz önüne alırsak uzun dönemde de orşiopeksinin başarısını değerlendirmede tek başına yetersiz kalabilir. Tek taraflı kriptorşidizm, yetişkinlikte artan infertilite riski ile beraberdir. Tek taraflı kriptorşidizm nedeniyle başarılı orşiopeksi uygulanan çocukların yetişkin dönemlerinde \%30'a kadar varan oranda subfertilite riski vardir (28-29). Bu oran bilateral kriptorşidizm için ameliyat olan hastalarda \%54'e kadar artmıştır. Orşiopeksi sonrası testis fonksiyonlarının belirlenmesi yetişkin dönemde fertilite kapasitesini göstermede bir belirteç olabilir. Diğer bir sertoli hücre belirteci olan inhibin seviyelerin spermatogenezi ve testiküler fonksiyonu göstermede potansiyel bir belirteç olabileceği çalışmalarda gösterilmiştir (30). Benzer şekilde inhibin düzeylerinin, geçmişinde kriptorşidizm olan erkeklerde infertilitenin bir göstergesi olan bebeklik döneminde azalan spermatogonia sayısıyla korele olduğu gösterilmiştir (31-33). IT hastalarında izlenen AMH konsantrasyonu, sertoli hücrelerinin işlevsel olduğunu ve bu aktivitenin orşiopeksi ile korunabileceğini gösterir. (12) Ameliyat öncesi ve sonrası AMH düzeylerinin karşılaştırılması da tedavinin etkinliğini belirlemede faydalı olabileceği belirtilmiştir (12). Çalışmamızda orşiopeksi operasyonunu takiben altıncı ay kontrolünde serum AMH değerlerinde preoperatif döneme göre istatistiksel anlamlı artış izledik. Komarowska ve ark. tek taraflı orşiopeksi uygulanan takip hastalarında birinci y1l sonunda serum AMH değerlerinde izlenen artışın istatistiksel anlamlı olmadığını belirtmişlerdir (34). Çalışmamıza benzer yaş ve hasta grubu içeren ve farklı olarak kontrol grubu hastaları da içeren başka bir çalışmada ise orşiopeksi sonrası altınc1 ayda kontrolde serum AMH düzeylerinin artmadığı ama stabil kaldığ1 gösterilmiştir ve bu bulgu yazarlara sertoli hücrelerinin ve seminifer tübüler yapıların bütünlüğünün orşiopeksi ile korunduğunu düşündürmüştür (24).

\section{Sonuç}

Orşiopeksi sonrası bazal değere göre serum AMH düzeylerininde izlediğimiz artış, orşiopeksi ile sertoli hücrelerinin ve seminifer tübüler yapıların bütünlüğünün ve gonadal fonksiyonun korunduğunu düşündürmektedir. Çalışmamızın eksik yönleri, kontrol grubu hastaların olmaması ve göreceli olarak az hasta sayısıdır. Orşiopeksinin serum AMH seviyeleri üzerinde değişimini araştırmak için bulgularımız daha yüksek vaka sayılı ve bilateral palpe edilen/edilemeyen gibi daha ciddi tipte testis migrasyon anomalilerini içeren çalışmalarla desteklenmelidir. Uzun takip süreli çalışmalarla ise yetişkin dönemde fertile potansiyelerinin takibi ile $\mathrm{AMH}$ değerinin orşiopeksi sonrası testis fonksiyonlarının korunduğunu göstermedeki prediktif değeri desteklenecektir. 


\section{KAYNAKLAR}

1. Thong MK, Lim CT, Fatimah H. Undescended testes: Incidence in 1002 consecutive male infants and outcome at 1 year of age. Pediatr. Surg. Int. 1998, 13: 37-41.

2. John Radcliffe Hospital Cryptorchidism Study Group. Cryptorchidism: A prospective study of 7,500 consecutive male births, 1984-8. Arch. Dis. Child. 1992; 67: 892- 899.

3. Berkowitz G.S., Lapinski R.H. Risk factors for cryptorchidism: a nested case-control study. Paediatr. Perinat. Epidemiol. 1996, 10: 39-51.

4. Virtanen HE, Cortes D, Rajpert-De Meyts E. Development and descent of the testis in relation to cryptorchidism. Acta Paediatr. 2007, 96;622627.

5. Hutson JM, Hasthorpe S, Heyns CF. Anatomical and functional aspects of testicular descent and cryptorchidism. Endocr. Rev. 1997,18; 259-280

6. Hutson JM, Sasaki Y, Huynh J, Yong E, Ting A. The gubernaculum in testicular descent and cryptorchidism. Turk J Pediatr.2004; 46 (suppl):3-6

7. Hutson JM, Lopez-Marambio FA. The possible role of AMH in shortening the gubernacular cord in testicular descent: a reappraisal of the evidence. J Pediatr Surg. 2017; 52:1656-60.

8. Hutson JM, Balic A, Nation T, Southwell B. Cryptorchidism. Semin Pediatr Surg. 2010; 19:215-24.

9. Grinspon RP, Rey RA. Anti-Mullerian hormone and Sertoli cell function in pediatric male hypogonadism. Horm Res Paediatr 2010;73:8192.

10. Tyrvainen E, Turpeinen U, Hamalanen E, Stenman UH. Increased activity of thehypothalamic-pituitary-testicular axis in infancy results in increased androgen action in premature boys. J Clin Endo- crinol Metab 2011;96:98-105.

11. Josso, N., Di Clemente, N., TGF-beta family members and gonadal development. Trends In Endocrinol And Metabolism.1999; 10: 216-22.

12. Yamanaka J, Baker ML, Metcalfe SA, Hutson JM. Serum levels of Mullerian inhibiting substance in boys with cryptorchidism. J Pediatr Surg.1991; 26:621-23

13. Lee MM, Donahoe PK, Silverman BL, et al. Measurements of serum Mullerian inhibiting substance in the evaluation of children with non palpable gonads. N Eng J Med.1997;336:1480-86

14. Tran D, Picard JY, Vigier B, Berger R, Josso N. Persistence of Mullerian ducts in male rabbits passively immunized against bovine antiMullerian hormone during fetal life. Dev Biol. 1986; 116:160-67

15. Hutson JM, Baker M, Terada M, Zhou B, Paxton G. Hormonal control of testicular descent and the cause of cryptorchidism. Reprod Fertil Dev. 1994;6:151-6.

16. Lee MM, Donahoe PK, Hasegawa $\mathrm{T}$ et al. Müllerian inhibiting substance in humans: normal levels from infancy to adulthood. J. Clin. Endocrinol. Metab. 1996; 81: 571-76.
17. Aksglaede L, Sørensen K, Boas M, et al. Changes in anti-Mullerian hormone (AMH) the life span: a population-based study of 1027 healthy males from birth (cord blood) to the age of 69 years. $J$ Clin Endocrinol Metab 2010;95:5357-64.

18. Kuiri-Hanninen T, Seuri R, Tyrvanen E, et al. Increased activity of the hypothalamic-pituitarytesticular axis in infancy results in increased androgen action in premature boys. J Clin Endocrinol Metab 2011;96:98-105.

19. Grinspon RP, Gottlieb S, Bedecarras P, Rey RA. Anti-Müllerian hormone and testicular function in prepubertal boys with cryptorchidism. Front Endocrinol (Lausanne) 2018; 9: artc no:182.

20. Ahmed SF, Keir L, McNeilly J, Galloway P, O'Toole S, Wallace AM. The concordance between serum anti-Mullerian hormone and testosterone concentrations depends on duration of hCG stimulation in boys undergoing investigation of gonadal function. Clin Endocrinol (Oxf). 2010 ;72:814-9.

21. Guibourdenche J, Lucidarme N, Chevenne D et al. Anti-Müllerian hormone levels in serum from human foetuses and children: pattern and clinical İTerest. Mol and Cell Endoc. 2003; 211: 55-63.

22. Komarowska MD, Milewski R, Charkiewicz R et al. Are anti-Müllerian hormone and its receptor polymorphism associated with the hormonal condition of undescended testes? Adv. in Med. Sci. 2016; 61: 288-92

23. Demircan M, Akınc1 A, Mutus M. The effects of orchiopexy on serum anti-Müllerian hormone levels in unilateral cryptorchid infants. Ped Surg Int. 2006; 22:271-73.

24. Baker ML, Metcalfe SA, Hutson JM.Serum levels of Müllerian inhibiting substance in boys from birth to 18 years, as determined by enzyme immunoassay. J Clin Endocrinol Metab. 1990; 70: 11-15.

25. Lee MM, Donahoe PK, Silverman BL, et al. Measurements of serum Müllerian inhibiting substance in the evaluation of children with non palpable gonads. N. Engl. J. Med. 1997; 336: 1480-86.

26. Virtanen HE, Bjerknes $\mathrm{R}$, Cortes $\mathrm{D}$, et al. Cryptorchidism: classification, prevalence and long-term consequences. Acta Paediatr. 2007; 96: 611-16.

27. DS Engeler, Hosli PO, John $\mathrm{H}$, et al. Early orchiopexy: prepubertal İTratubular germ cell neoplasia and fertility outcome. Urology. 2000; 56 :144-148

28. PA Lee, LA O'Leary, Songer NJ, Coughlin MT, Bellinger MF , LaPorte RE. Paternity after unilateral cryptorchidism: a controlled study. Pediatrics. 1996; 98:676-79

29. Klingmuller D, Haidl G. Inhibin B in men with normal and disturbed spermatogenesis. Hum Reprod 1997;12:2376-8.

30. Cortes D, Thorup J, Hogdall E, NorgaardPedersen B, Petersen BL, Hogdall C. The relation of germ cells per tubule in testes, serum inhibin B and FSH in cryptorchid boys. Pediatr Surg Int.2007; 23:163-9. 
31. Verkauskas G, Malcius D, Eidukaite A, et al. Prospective study of histological and endocrine parameters of gonadal function in boys with cryptorchidism. J Pediatr Urol. 2016;12: 238.e16.

32. Hadziselimovic F, Herzog B. Importance of early postnatal germ cell maturation for fertility of cryptorchid males. Horm Res.2001;55:6-10.

33. Komarowska MD, Hermanowicz A, Matuszczak $\mathrm{E}$, et al. Anti-Müllerian hormone levels in serum 1 year after unilateral orchiopexy. $J$ Pediatr Endoc and Met. 2012; 25:1073-76.

๑Copyright 2022 by Osmangazi Tıp Dergisi - Available online at tip.ogu.edu.tr @Telif Hakkı 2022 ESOGÜ Tıp Fakültesi - Makale metnine dergipark.org.tr/otd web sayfasından ulaşılabilir. 